\title{
Development of Educational Curricula Based on Digital Microscopes
}

\author{
G. S. Casuccio and S. K. Kennedy
}

RJ Lee Group, Inc., 350 Hochberg Road, Monroeville, PA 15146

Although the scanning electron microscope (SEM) is an essential scientific research tool, its utilization in education has been modest. Only a handful of high schools in the U.S. have access to SEM instrumentation, and availability at colleges and universities at the undergraduate level is limited. This is unfortunate because the image-based, interactive nature of the SEM appeals to the inquisitive nature of students. With its ability to provide highly detailed images of microscopic features as well as information on composition, the SEM is an ideal analytical tool to incorporate into science curricula.

In an effort to help bring the SEM into the classroom, RJ Lee Group has been working for several years with educators to explore new and innovative ways to utilize the SEM to enhance science classes. These efforts have lead to the development of an SEM microscopy laboratory at a middlehigh school in southwestern Pennsylvania, incorporating a unique school-to-work component. Complementing the use of the local microscope, RJ Lee Group has developed WebSEM technology that allows Internet access to the SEM at remote locations. While programs such as these are major steps forward, any program based on access to real analytical instrumentation is unlikely to serve all students on a continuing basis.

To move the SEM experience into the classroom on a grand scale will require development of SEM simulators. Effective simulation would retain the excitement while permitting all students to have access to "SEM" technology throughout a school year. With funding support from the National Science Foundation [1], RJ Lee Group has developed CD and Web-based versions of an SEM simulator that permit "specimens" to be examined and analyzed in a manner similar to a real SEM. This technology has the potential to open the door to widespread use of the SEM in the classroom. The technology can also be expanded to other image-based analytical instruments such as highquality light microscopes.

Development of microscope simulators is only half the solution in that they will have limited impact in education if it is left to teachers to understand the underlying technology and to develop and implement their own lessons. To this end, RJ Lee Group is developing Web-based curriculum extensions which provide background information on the technology, content area, and defined lesson plan activities. These modules are being developed with the support of educators and the assistance of ASSET Inc., an independent, non-profit organization developed to help educators foster outstanding student achievement in science and technology in the Pittsburgh, PA area.

SEM and light microscope simulators provide for new opportunities to bring microscopy into prominence in science education. Combined with effective curriculum, the simulators will enable students to perform more sophisticated scientific experiments and help schools meet the increasing mandates for scientific literacy.

[1] This research was supported by NSF SBIR Phase II Grant \#DMI-0321679. 


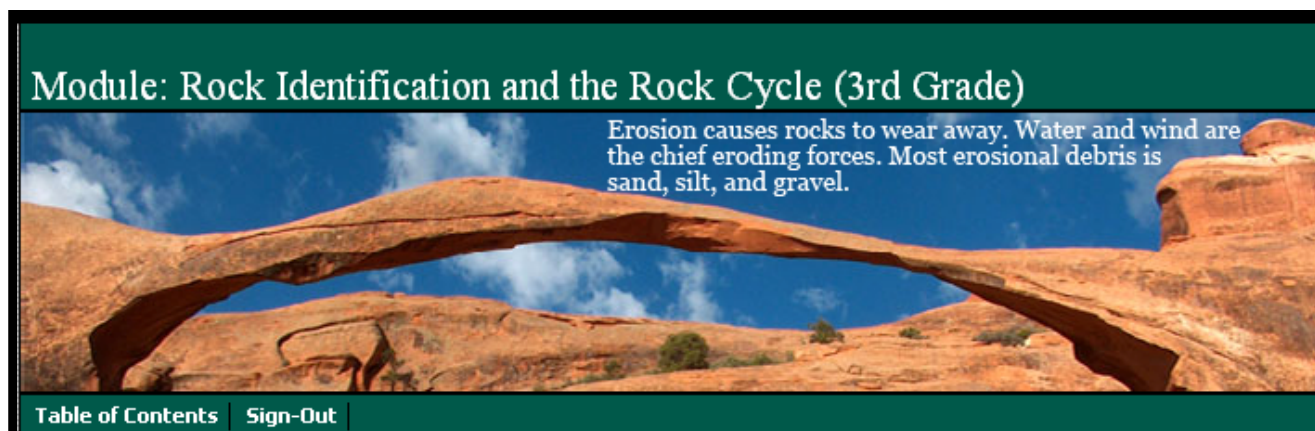
Table of Contents Sign-Out

\section{Resources}

Glossary

Suggested Links

\section{Table of Contents}

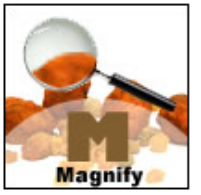

Investigation 1: Scientific Tools - Maqnification

Scientists use many tools, including the optical microscope. In this Investigation, students learn what a microscope is, and how to use a microscope simulator. Before using the microscope simulator on unfamiliar material such as a rock, the student investigates a dime. As an activity, the student compares observations made using the unaided eye with those made using the microscope simulator.

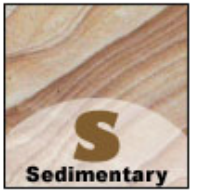

Investigation 2: Explore a Sedimentary Rock

In general, sedimentary rocks are formed of fragments or dissolved material derived from pre-existing rocks. In this investigation, students explore a conglomerate that was formed from rock fragments. The grains are described and the students explore why the grains look the way they do.

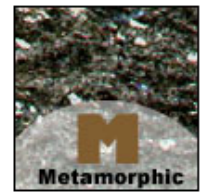

Investigation 3: Explore a Metamorphic Rock

Metamorphic rocks are formed by increased pressure and temperature that changes the composition and texture of the grains. In this investigation, students changes the composition and texture of the grains. In this investigation, students
explore a gneiss. The grains are described and the students explore why the grains look the way they do.

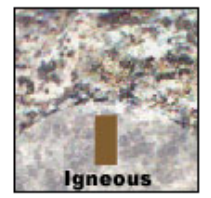

Investiqation 4: Explore an Iqneous Rock

Igneous rocks are formed by the cooling of melted material deep below (magma) or at (lava) the earth's surface. In this investigation, students explore a white granite that was formed deep below the earths surface. The grains are described and the students explore why the grains look the way they do.

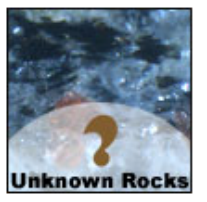

Investiqation 5: Classification of Rocks

In previous investigations, the students observed the grain characteristics of known rocks. In this investigation, the students explore a new example of each rock type and use the grain characteristics to identify their type.

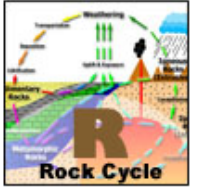

Investiqation 6: The Rock Cycle

In each investigation, the characteristics of the grains were related to how each rock was formed. In this investigation, the relation between the three rock types are explored.

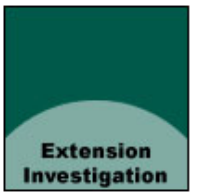

Extension Investigation: Rocks in National Parks

The rocks that have been explored in these investigations are not in their original context. In this investigation, the students use the internet to gather information concerning the types of rocks that can be observed in various National Parks across the country.

Fig. 1. Example of Web-based curriculum being developed for Rocks \& Minerals lesson extension. 